\title{
PerCursos
}

\section{A polícia política em tempos de Ditadura Militar (1964-1985): a atuação da Delegacia de Ordem Política e Social no Espírito Santo}

\begin{abstract}
Resumo
O presente artigo tem como propósito analisar e caracterizar os aspectos gerais da organização e do funcionamento da Delegacia de Ordem Política e Social do Espírito Santo (DOPS/ES), entre os anos de 1964 e 1985. Atuante na sociedade capixaba desde os anos 1930, esse órgão teve importante papel nas ações repressivas do regime estabelecido pelo golpe civil-militar de 1964, atuando como uma polícia política que vigiou e reprimiu os setores "indesejáveis" do corpo social, como um dos órgãos da rede de repressão e informação que articulou o combate ao que definia como focos de subversão no país. Para tanto, este trabalho se baseia na aproximação com parte da documentação produzida pelo referido órgão durante sua atuação no período na vida sócio-política espírito-santense, e dos resultados de recentes trabalhos realizados por outros pesquisadores que também fundaram suas investigações nos arquivos da DOPS/ES.
\end{abstract}

Palavras-chave: Ditadura Militar. Espírito Santo. Repressão política. DOPS/ES.

\author{
Leonardo Baptista \\ Mestre em História pela \\ Universidade Federal do Espírito \\ Santo - UFES. \\ Brasil \\ leobapt@gmail.com
}

\footnotetext{
Para citar este artigo:

BAPTISTA, Leonardo. A polícia política em tempos de Ditadura Militar (1964-1985): a atuação da Delegacia de Ordem Política e Social no Espírito Santo. PerCursos, Florianópolis, v. 21, n.46, p. 217 - 243, maio/ago. 2020.
} 


\title{
Political police in times of Military Dictatorship (1964- 1985): the performance of the Police of Political and Social Order in Espírito Santo
}

\begin{abstract}
The purpose of this article is to analyze and characterize the general aspects of the organization and functioning of the Police Station of Political and Social Order of Espírito Santo (DOPS/ES) between 1964 and 1985. Active in the Espírito Santo society since the 1930s, this body played an important role in the repressive actions of the regime established by the 1964 civil-military coup, acting as a political police that monitored and repressed the "undesirable" sectors of the social body, as one of the organs of the network of repression and information that articulated the fight against what it defined as foci of subversion in the country. For this purpose, this work is based on the approximation with part of the documentation produced by the referred organ during its performance in the period in the socio-political life of Espírito Santo, and the results of recent works carried out by other researchers who also founded their investigations in the DOPS/ES archives.
\end{abstract}

Keywords: Military Dictatorship. Espírito Santo. Political repression. DOPS/ES. 


\section{Introdução: o acesso aos arquivos da repressão e o impulso à historiografia}

\section{brasileira}

Os recentes avanços da legislação referente ao acesso à informação no Brasil abriram novos horizontes às pesquisas historiográficas. Nesse processo, destaca-se a conquista da Lei n. 12.527/2011 (Lei de Acesso à Informação), que regulamentou o tratamento, a disponibilidade, o acesso, entre outras providências, a informações acerca da administração pública brasileira. Em vigor desde 16 de maio de 2012, essa norma tem possibilitado, em certa medida, o contato da sociedade com documentos produzidos pelo Estado brasileiro em suas diversas instâncias de atuação e em diferentes conjunturas. Apesar da existência de entraves à consulta dos arquivos, ela representou para historiadores, estudantes, jornalistas, enfim, para inúmeros interessados, a possibilidade de utilizarem documentos até então vetados à pesquisa (FAGUNDES, 2013, p. 296).

Nesse processo, ainda deve ser ressaltada a importância da criação da Comissão Nacional da Verdade (CNV) (Lei n. 12.528/2011) que, entre 2012 e 2014, dedicou-se, em diversas regiões do país, a examinar e esclarecer as graves violações de direitos humanos praticadas pelo Estado brasileiro entre os anos de 1946 e 1988, a fim de efetivar o direito à memória e à verdade histórica. Os trabalhos da CNV foram responsáveis, nos últimos anos, pela produção de novas evidências históricas acerca desses contextos, a partir da descoberta de documentos e da produção de depoimentos com agentes envolvidos com a repressão e suas vítimas no passado.

A partir dessas inovações legais, abriu-se o acesso a um amplo acervo de documentos dos períodos autoritários da história brasileira, possibilitando aos historiadores a oportunidade de lançarem novos problemas e produzirem novas perspectivas sobre o regime ditatorial que vigorou no Brasil entre os anos de 1964 e 1985. Dessa forma, por exemplo, com base nesses documentos, podemos melhor nos aproximar do cotidiano das atividades repressoras e seus impactos sobre a sociedade brasileira naqueles tempos. 
Nessa direção, os estudos sobre os órgãos responsáveis pela repressão política da ditadura militar podem ser potencializados. Como resultado da rotina diária de vigilância e controle dos focos de subversão no país, o aparelho repressivo ditatorial produziu uma gama de registros de suas atividades, gerando os chamados arquivos da repressão. Caroline Silveira Bauer e René E. Gertz definem esse tipo de documentação como,

[...] conjuntos documentais produzidos pelos órgãos de informação e segurança do aparato estatal em ações repressivas, durante períodos não democráticos.

Em sua maioria, os arquivos da repressão se compõem de registros elaborados ou incorporados a partir da ação policial cotidiana (fichas pessoais, depoimentos, prontuários, dossiês, relatórios, informações, ordens de busca e prisão etc.), mas também de documentos roubados (livros, publicações, correspondências pessoais, documentos de organizações etc.), ou de declarações tomadas em interrogatórios que desrespeitavam tanto o código penal (duração do interrogatório, horário em que eram feitos, presença de testemunhas etc.), quanto os Direitos Humanos (tortura física e psicológica); [...] [Nessa categoria] ainda podem ser incluídos objetos sequestrados junto com as vítimas, no momento da prisão, e documentação produzida pelas organizações de Direitos Humanos em sua busca por informações sobre atingidos e de denúncia de ilegalidades e de violências praticadas. (BAUER, GERTZ, 2011, p. 177)

Expressando a rotina das atividades repressivas, esses documentos são capazes de revelar a lógica de funcionamento e o próprio caráter dos órgãos que os produziram (CAMARGO, 2009). Partindo desse pressuposto, entendemos que, por meio desses arquivos, podemos nos aproximar, por exemplo, da realidade produzida e vivida pela polícia política, e em nosso caso, dos trabalhos desenvolvidos pela Delegacia de Ordem Política e Social do Espírito Santo (DOPS/ES) entre os anos de 1964 e 1985.

Como um dos importantes braços da repressão estatal da Ditadura Militar Brasileira (1964-1985) no Espírito Santo, a DOPS/ES arquivou enorme quantidade e diversidade de registros de suas atividades ${ }^{1}$, atestando o seu papel no controle e combate

\footnotetext{
${ }^{1} \mathrm{O}$ acervo é constituído por correspondências recebidas e expedidas por órgãos da Secretaria de Segurança Pública, assim como, ordens de serviços, relatórios, ofícios internos e externos, informes, radiogramas, encaminhamentos, pedidos de busca, protocolos de envio/recebimento de informações. Contém ainda,
} 
ao que o regime ditatorial definia como "subversão" em âmbito regional naquele contexto. Desde 1991, seu acervo está sob a custódia do Arquivo Público do Estado do Espírito Santo (APEES), mas somente a partir de 2009 ele começou a ser organizado, quando o APEES passou a integrar o "Projeto Memórias Reveladas”, do Arquivo Nacional (FAGUNDES, 2011, p. 31).

Com base no contato com tais documentos e na recente produção historiográfica acerca da relação da DOPS/ES com diferentes segmentos da sociedade capixaba, é que nos propomos, por meio deste artigo, a apresentar aspectos gerais da atuação da polícia política no contexto social e político capixaba em tempos de Ditadura Militar (1964-1985).

Antes de partirmos para esse objetivo, pressupomos a necessidade de definir a polícia política como um dos instrumentos da segurança pública brasileira e sua história no país e no Espírito Santo, a fim de melhor entendermos sua essência e sua trajetória histórica.

\section{A polícia política: definição e um breve histórico no Brasil}

A polícia política se refere a um tipo de policiamento que, em diferentes situações históricas, assumiu a tarefa de combate via vigilância e repressão ao que, em um determinado contexto social e político, considera-se como crime político. Ou seja: ações que atentam contra a ordem e segurança política estabelecidas. Segundo Marília Xavier,

[...] o termo polícia política tem sido utilizado, tradicionalmente, para designar um tipo especial de modalidade de polícia que desempenha uma função preventiva e repressiva na história do Brasil, tendo sido criada com fins de entrever e coibir reações políticas adversas, armadas ou não que comprometessem a 'ordem e a segurança pública'. (XAVIER, 1996, p. 32)

requerimentos, atestados de conduta de ideologia política, depoimentos, inquéritos policiais, fotografias, jornais, recortes de jornais, livros, cartazes e panfletos. Bem como dossiês referentes à investigação de pessoas, instituições públicas e privadas, partidos políticos, sindicatos, organizações clandestinas, manifestações, atos públicos, eventos, eleições, movimentos grevista e estudantil, organizações religiosas, Aliança Nacional Libertadora e Ação Integralista Brasileira, além de fichas policiais de identificação contendo informações sobre indivíduos, instituições, investigações, eventos, municípios, entre outros (ARQUIVO NACIONAL, 201-). 
No Brasil, a polícia política é estruturada oficialmente entre as décadas de 1920 e 1930. É nesse contexto que, paulatinamente, surgirão em níveis nacionais e estaduais, órgãos estatais específicos para a contenção do criminoso político. Apesar desse marco histórico, podemos afirmar que, a preocupação com a manutenção da ordem e da segurança do Estado brasileiro já fazia parte das atividades da polícia brasileira desde os primeiros momentos da Primeira República (1889-1930). Em 1907, por exemplo, foi criado no Distrito Federal, o Corpo de Investigações e Segurança Pública da Polícia Civil, primeira instituição policial com função de também reprimir crimes políticos, ainda que sob essa designação estivesse qualquer tipo de desordem pública (MENDONÇA, 1998, p. 381). Além disso, a legislação republicana acerca da segurança pública nas duas primeiras décadas do século XX, como nos demonstra Xavier (1993), já garantia como privativo ao aparato policial o tratamento da ordem política no país.

A seguida criação de órgãos e setores policiais voltados, especificamente, para o combate ao crime político desde o início do século $\mathrm{XX}$, insere-se num processo de especialização das atividades de segurança no tocante ao combate aos setores considerados “indesejáveis" da sociedade pelas elites republicanas (XAVIER, 1993, p. 33). Tal fenômeno surgiu como resposta ao recrudescimento das agitações políticas e sociais que ocorreram na sociedade brasileira na década de 1920, contexto que refletia a conjuntura de instabilidade econômica e social emergente no mundo ocidental pósGrande Guerra (1914-1918), abrindo caminho para revoluções sociais. Entre essas, são fundamentais os impactos internacionais da Revolução Bolchevique, na Rússia, em 1917, que estimulou movimentos sociais pelo mundo capitalista, assustando as camadas dominantes, inclusive as brasileiras.

A década de 1920, no Brasil, foi marcada por uma grande ebulição política e social. As lutas operárias se intensificaram nas grandes cidades. O comunismo se organizou institucionalmente no país com a fundação do PCB (1922). No campo cultural, a Semana de Arte Moderna (1922) também figurou como um dos elementos contestadores das condições nacionais. Entre as Forças Armadas, um segmento de jovens tenentes 
questionou o sistema oligárquico que caracterizava a República e promoveu revoltas (MOTTA, 2006, p. 56).

Reagindo a esses focos de instabilidade política, as autoridades brasileiras criaram os primeiros organismos federais e estaduais especialmente destinados à vigilância e contenção de sujeitos e grupos considerados subversivos. Nesse sentido, considera-se como marco inicial da especialização de uma polícia política no país, a criação, no Distrito Federal, da $4^{\mathrm{a}}$ Delegacia Auxiliar que contava com a Seção de Ordem e Política Social, para qual se tributava a função de combater as mobilizações anarquistas, comunistas, e de operários brasileiros ou estrangeiros (MENDONÇA, 1998, p. 380). Nos anos seguintes, outros estados da federação² lançaram seus próprios órgãos de polícia política. Em 1924, por exemplo, o governo paulista monta a Delegacia de Ordem Política e Social, fundando a sigla DOPS, adotada por outros estados da federação em seguida, originando uma nomenclatura que ficará famosa na história política do país.

Dessa forma, a especialização do combate ao crime político pelo governo republicano brasileiro expressava sua marca autoritária, mostrando sua incapacidade em resolver os conflitos e oposições internas por vias democráticas (MOTTA, 2006, p. 56). Esse processo culminou com a formalização institucional das polícias políticas no Brasil, na década de 1930, no contexto do governo de Getúlio Vargas (1930-1945). Em 1933, diante da necessidade de aprofundar o combate aos seus opositores políticos, Vargas ampliou e consolidou a formação de um policiamento especializado em combater os “inimigos da ordem” no país com a criação da Delegacia Especial de Segurança Política e Social (DESPS) (MENDONÇA, 1998, p. 381). Ao mesmo tempo, e a reboque desse processo, as DOPS se espalhavam pelos estados brasileiros.

\footnotetext{
2 Rodrigo Patto Sá Motta (2006, p. 56) faz interessante interpretação do caráter regional das polícias políticas no país, atribuindo-lhes especificidades na sua organização e atuação em cada contexto de origem. Para o referido historiador, as Delegacias de Ordem Política e Social, conhecidas pela sigla DOPS, para além de respostas às instabilidades políticas e sociais da década de 1920, são fruto de outro aspecto do estado republicano que buscava se consolidar. Sua criação e manutenção em âmbito estadual refletem os anseios das elites regionais em resguardar suas autonomias locais e assegurar os princípios do federalismo diante do poder central. Dessa forma, as DOPS seriam pequenos exércitos estaduais que, se necessário, poderiam ser utilizados para se contrapor ao exército nacional, comandado pela Presidência da República. Essa tradição autônoma e regional resistirá, pelo menos até a década de 1960, às tentativas de centralização da polícia política por parte dos governos federais, inclusive, diante do centralismo da política varguista (1930-1945).
} 
A radicalização ideológica entre movimentos e partidos de extrema esquerda e direita, respectivamente, a militância de comunistas e integralistas, influenciaram para a decretação da Lei de Segurança $\mathrm{Nacional}^{3}$ da década de 1930, dando amplo amparo legal ao trabalho repressivo dos agentes das polícias políticas no país. A partir de 1946, a queda do Estado Novo (1937-1945) e a abertura do processo de democratização do país não interferiram nos quadros das polícias políticas estaduais. As DOPS não foram extintas.

Apesar de passarem a ser supervisionadas pelo recém-criado Departamento Federal de Segurança (DFSP), de 1944, elas ainda estiveram resguardadas em sua autonomia, combatendo e controlando seus inimigos em seus respectivos estados de origem. Entre os anos 1950 e 1960, num contexto marcado pelas disputas ideológicas da Guerra Fria, no qual o Brasil se alinhava aos Estados Unidos da América, a ideia era compatibilizar democracia e repressão. Nesse contexto, as polícias políticas foram fundamentais à segurança pública brasileira, na medida em que, por sua experiência no combate à subversão, poderiam ser aproveitadas para repelir a "ameaça" comunista da sociedade brasileira, já que se alimentavam de uma obsessão repressiva anticomunista desde os anos $1930^{4}$ (MOTTA, 2006, p. 58-59). Assim, a polícia política permaneceu vital para o Estado brasileiro no seio do regime democrático vigente entre os anos de 1946 e início de 1964.

Durante o regime ditatorial instalado a partir de abril de 1964, ocorreu a criação de um aparato repressivo de caráter nacional controlado pelas Forças Armadas, que buscou centralizar as ações de repressão e informação contra os indivíduos e organizações

\footnotetext{
${ }^{3}$ A Lei de Segurança Nacional refere-se à Lei $n^{\circ} 38$, promulgada em 4 de abril de 1935, que definia crimes contra a ordem política e social. Sua principal finalidade era transferir para uma legislação especial os crimes contra a segurança do Estado, submetendo-os a um regime mais rigoroso, com o abandono das garantias processuais. Apesar de legislações anteriores já legitimarem a repressão política, segundo Motta (2006), nada tinha sido tão abrangente e rigoroso como essa regra. Ela foi reformulada em dezembro de 1935, e substituída em maio de 1938 pelo decreto-lei $n^{\circ} 431$, que a atualizava numa versão mais dura e severa, introduzindo, por exemplo, a pena de morte para crimes políticos.

4 Segundo Motta (2002), as forças policiais foram tomadas por uma obsessão anticomunista. Por anticomunismo se entende um conjunto de atividades que expressam o sentimento de oposição ao pensamento comunista ou ao que a ele é identificado. No Brasil, tais práticas partiram do Estado e da própria sociedade. Para o referido autor, apesar de encontrarmos desde a década de 1920 evidências desse fenômeno no Brasil, é somente a partir do levante armado comunista organizado pela Aliança Nacional Libertadora, popularmente chamado de "Intentona Comunista", em 1935, somado à expansão da influência do PCB, que se disseminou e consolidou o anticomunismo no Brasil, elevando os comunistas à condição de principais alvos das DOPS no país.
} 
opositoras ao regime. No entanto, as DOPS não foram desarticuladas. Pelo contrário, mais uma vez, o Estado brasileiro aproveitou de sua experiência repressiva, e a incorporou à rede de informações e repressão. Dessa forma, as polícias políticas estaduais funcionaram, entre 1964 e 1985, como um elo na articulação da repressão em âmbito regional aos trabalhos dos órgãos militares federais.

\section{O aparato repressivo da Ditadura Militar Brasileira (1964-1985): os Sistemas de Segurança}

\section{e Informação e as DOPS}

Desde os primeiros passos do governo instalado pelo golpe civil-militar iniciado em março de $1964^{5}$, é evidente a dedicação à repressão política por setores militares que buscavam operar o que consideravam uma "profunda limpeza" na sociedade brasileira, afastando-a da corrupção, do comunismo, da desordem e da subversão. Segundo Mariana Joffily (2014, p. 158), a repressão política “[...] abarca uma diversidade extensa de atos, entre os quais incluem cassações, intervenções, censura, leis autoritárias, ameaças, vigilância, suspeição exacerbada, demissões injustificadas [...]”.

Esse conjunto de ações foi lançado pelo regime ditatorial que vigorou entre $1964 \mathrm{e}$ 1985 no Brasil no combate às oposições políticas. Nesse contexto, sob a influência ideológica da Doutrina de Segurança Nacional ${ }^{6}$, a noção de crime político foi ampliada aos olhos dos militares que se lançaram no combate à "subversão" a partir de 1964. A Constituição de 1967 afirmava a noção de "inimigo interno", elevando o criminoso

\footnotetext{
5 Já nos primeiros dias de governo militar do presidente general Castello Branco (1964-1967), respaldados legalmente pelo Ato Institucional de 9 de abril de 1964 - depois chamado de Al-1 - prisões políticas, exílios, tortura, mortes, cassação de mandatos, suspensão de direitos políticos e anulação da estabilidade dos funcionários públicos civis e militares foram lançados contra setores considerados "indesejáveis" da sociedade (GASPARI, 2002, pp. 130-131).

${ }^{6}$ Segundo Carlos Fico (2001, pp. 40-42), a Doutrina de Segurança Nacional corresponde a um conjunto de pressupostos ideológicos e planos de ação produzidos pela Escola Superior de Guerra baseado na articulação entre segurança nacional e desenvolvimento. Por ela, entendia-se que o Brasil se integrava às disputas ideológicas da Guerra Fria, apontando a importância estratégica do país no cenário geopolítico mundial. Afirmavam-se as fragilidades da vida política brasileira, que seria formada por uma população despreparada e com políticos populistas e corruptos, tornando o país vulnerável ao comunismo. Portanto, para essa ideologia, seriam coerentes medidas logrando a possibilidade do Brasil se tornar uma grande potência nesse cenário, o afastamento das ameaças comunistas, como a elaboração de mecanismos internos de combate aos mesmos, assim como a construção de caminhos para o país, diante de uma possível guerra entre capitalistas e comunistas.
} 
político ao patamar de "verdadeira ameaça" à segurança nacional (JOFFILY, 2013, pp. 2829). Assim, a violenta repressão política foi compreendida por parte da classe militar em termos de uma "Guerra Contrarrevolucionária". O criminoso político era o principal inimigo da nação. Ele poderia estar entre os cidadãos comuns, que influenciados pelo Movimento Comunista Internacional $(\mathrm{MCl})$, poderia violentamente desestabilizar o governo (JOFFILY, 2014, p. 161).

Visando legitimar legalmente o planejamento e a execução da repressão, o Estado brasileiro lançará mão de toda uma legislação baseada em Atos Institucionais, Lei de Segurança Nacional, decretos secretos e novas Constituições que possibilitaram juridicamente as atividades repressivas na sociedade. Ao mesmo tempo, órgãos militares foram criados e/ou ampliados para executar a vigilância e a contenção de subversivos em todos os setores da vida nacional.

A construção de toda estrutura normativa e organizacional da repressão no país a partir de 1964, vista em retrospectiva, pode ser entendida com um processo de radicalização repressiva. Tal fenômeno tem origens no papel desempenhado por militares identificados a uma ala radical da classe militar, conhecida historicamente como "linhadura"7. Segundo Carlos Fico (2001), esses indivíduos agiam como um grupo de pressão nos corredores do governo ditatorial, sendo fundamentais para o endurecimento do regime, ao forçar condições para a criação de mecanismos legais, burocráticos e estruturais que encaminhassem o que consideravam como uma "necessária limpeza da sociedade".

\footnotetext{
7 Mariana Joffily (2013, p. 25) indica que a expressão "linha dura" designava um "grupo de militares de extrema-direita, disseminados pelos quartéis, que defendiam o uso da violência como instrumento de afirmação do poder". A autora aponta para a dificuldade em polarizar, como comumente se faz, uma ala moderada e outra dura no que tange à postura em relação à repressão política do regime, haja vista que indivíduos normalmente indicados ao primeiro grupo, defendiam em determinadas circunstâncias, posturas radicais. Nesse sentido, Carlos Fico (2001, p. 23) também alerta que, por militares, devemos entender um grupo de diferentes posições ideológicas e pensamentos diante do aparato repressivo do Estado. Deve-se ir além da divisão linha-dura/castelistas (moderados), haja vista que, no seio dessas correntes, nem todos os radicais defendiam a repressão violenta, aproximando-se dos moderados, nem estes tinham membros totalmente contra o uso da força para controlar a subversão. Uma tipologia desses indivíduos deve considerar mais seus posicionamentos políticos do que suas posturas diante dos inimigos do regime.
} 
Em 1967, ascende à presidência da República, o general Arthur Costa e Silva, o que significou a chegada da linha dura ao poder (ANGELO, 2009, p. 63). Ao mesmo tempo, nesse contexto, e principalmente a partir de 1968, cresceram as manifestações antigovernamentais da sociedade civil nas grandes cidades do país e os ataques de grupos da esquerda armada. Dessa forma, o anseio pela radicalização da repressão da ala radical encontrava, naquele momento, justificativas para o maior fechamento e endurecimento do regime autoritário (ANGELO, 2011).

Como marco fundamental e legal da radicalização da repressão no país, em 13 de dezembro de 1968, o governo brasileiro decretou o Ato Institucional $n^{\circ} 5$ (Al-5). Este, além de possibilitar a concentração de amplos poderes no Poder Executivo, reforçou os mecanismos de controle e repressão da sociedade, abrindo caminho jurídico para uma nova estrutura repressiva. O Al-5 concedeu maior liberdade de ação aos agentes da repressão, legalizando e institucionalizando práticas outrora ilegais e clandestinas (JOFFILY, 2013, p. 27). Abria-se o cenário dos "anos de chumbo" do governo do general Emílio Garrastazu Médici ${ }^{8}$ (1969-1973).

No contexto da onda repressiva que se abriu a partir de 1969 , ocorreu a consolidação e formalização dos Sistemas de Segurança e Informação do regime, uma rede de órgãos que assumiu a tarefa de espionar e combater os indivíduos considerados subversivos (FICO, 2001, pp. 17-18). Essa estrutura ficou conhecida como a Comunidade de Segurança e Informação e atuou, praticamente, até o fim do regime resistindo inclusive ao processo de distensão política do presidente general Ernesto Geisel (1974-1979) e de abertura democrática do seu sucessor, o também general João Batista Figueiredo (19791985).

O Sistema de Informações era constituído de um conjunto de órgãos e profissionais especializados na coleta e armazenamento de dados sobre a subversão no país. Nessa comunidade são centrais as ações do Serviço Nacional de Informações (SNI)99,

\footnotetext{
8 O general Médici foi eleito em 1969 por uma Junta Militar para ocupar o cargo deixado vago pelo falecimento de Arthur Costa e Silva naquele ano.

9 Importante citar que a criação do SNI se dá já em junho de 1964, no início do regime, demonstrando a precoce preocupação com a vigilância e a produção de informações sobre suspeitos por parte dos militares.
} 
que reunia e produzia informações de interesse para a segurança nacional, a partir de suas agências espalhadas pelo país. Ele alimentava o Sistema Nacional de Informações (SISNI), organismo que abastecia a presidência de dados importantes para a tomada de decisão das autoridades brasileiras ${ }^{10}$ (FICO, 2001, p. 81-83).

Também foi estruturada uma rede nacional de repressão sob o controle das forças armadas. Assim, criou-se o Sistema de Segurança Interna (SISSEGIN). Entre os seus tentáculos repressivos, destacou-se o Destacamento de Operações e Informações Centro de Operações de Defesa Interna (DOI-CODI) como uma polícia política brutal que planejava e executava ações de defesa interna contra a luta revolucionária da esquerda (FICO, 2001, pp. 116-122).

Nesse contexto, em âmbito estadual, as Delegacias de Ordem Política e Social (DOPS) auxiliavam a máquina repressiva nacional. Durante a ditadura militar, as DOPS atuavam em sintonia com os sistemas de informações, vigiando e contendo movimentos contestatórios (FAGUNDES, 2011, p. 304). Assim, as antigas polícias políticas estaduais foram aproveitadas como mais um tentáculo da rede repressiva estruturada no país, estabelecendo um elo entre a repressão em níveis regionais, e os órgãos centrais e nacionais dos sistemas de informações e segurança, produzindo, coletando, difundindo informações, e contendo a subversão no âmbito estadual.

De acordo com a tese da historiadora Marcília Gama da Silva (2007), os órgãos de informação e segurança que atuaram durante o regime instalado no país a partir de 1964 formavam uma rede de informações a serviço da repressão. Distribuídos em diferentes níveis hierárquicos de comando, e ideologicamente fundados na Doutrina de Segurança Nacional, as práticas e discursos dessa rede no combate ao que considerava como elementos subversivos da sociedade, eram cimentados na informação. Essa é entendida pela pesquisadora como um saber-poder que fora fundamental para ações de vigilância e repressão do Estado brasileiro, dando origem a uma mentalidade de informação que se difundia entre as forças de segurança do país, e por diversos setores da sociedade civil.

\footnotetext{
10 Os órgãos militares possuíam seus sistemas de informação específicos para assuntos militares, respectivamente o Centro de Informações do Exército (CIE), o Centro de Informações da Aeronáutica (CISA) e o Centro de Informações da Marinha (CENIMAR). Ver Fico (2001, p. 85).
} 
Assim, entidades de âmbitos nacional, estadual e municipal, estabeleciam um intenso intercâmbio de dados que coletavam e produziam a partir das atividades policiais de seus agentes junto à sociedade, formando um poderoso aparato burocrático informacional. Dessa forma, produziam-se conhecimentos que legitimavam e norteavam o controle social, disciplinando corpos e silenciando oposições, a fim de assegurar a manutenção do regime de governo estabelecido e seus projetos de sociedade e poder.

As DOPS, enquanto polícias políticas subordinadas às Secretarias Estaduais de Segurança Pública, são parte integrante dessa rede. Esses órgãos atuaram em âmbito regional por meio da vigilância, da censura e das operações de contenção, especializandose "nos processos de produção, coleta, manuseio, manipulação e processamento da informação, no objetivo de rastrear as ideias e comportamentos suspeitos" (SILVA, M., 2011, p. 281). Nesse sentido, a produção da informação a partir dos trabalhos dos agentes das DOPS, baseou-se em diversas atividades que almejavam construir o máximo de conhecimentos possíveis acerca dos suspeitos, o que servia à legitimação e ao direcionamento das operações de controle que empreendiam na sociedade brasileira.

Por tratar essencialmente do crime político e suas implicações, o DOPS acumula experiência que paralelamente constrói 0 seu perfil administrativo, interferindo diretamente em suas práticas, nas estratégias baseadas na vigilância, censura e repressão, amparadas na observação permanente da sociedade, pelo uso da escuta telefônica, da interceptação de correspondências, da investigação sistemática de algum fato ou pessoa, da vigilância em locais suspeitos, do acompanhamento de determinadas pessoas e locais por investigadores, da invasão de células comunistas, aparelhos ou qualquer local onde haja indícios de atividades subversivas aos olhos da polícia. (SILVA, M., 2007, p. 130)

A partir dessas conjecturas, partirmos agora para um olhar sobre as atividades da Delegacia de Ordem Política e Social do Espírito Santo (DOPS/ES) durante a Ditadura Militar (1964-1985). Para tanto, destacamos os resultados de algumas das recentes pesquisas que atentaram para a atuação desse órgão na vida política e social capixaba. 


\section{A atuação da Dops/ES em tempos de Ditadura Militar (1964-1985)}

A história da polícia política no Espírito Santo tem início oficial nos anos 1930. Até a década de 1980, esse tipo de atuação policial ocorreu, principalmente, sob a marca da Delegacia de Ordem Política e Social do Espírito Santo (DOPS/ES), órgão que ficara conhecido na sociedade capixaba por sua dedicação à repressão política contra indivíduos e grupos inseridos num rol de suspeitos de práticas subversivas contra ordem social e política nacional.

Como observou o historiador Pedro Ernesto Fagundes (2011, p. 304), a montagem, a burocratização, e a atuação da polícia política foi uma regra na história do Espírito Santo no século XX. Exercendo a vigilância, a repressão e a censura, inclusive em contextos democráticos, como o período entre 1946 e 1964, essa força de segurança pública revela sua matriz autoritária.

Dessa forma, entendemos que, para melhor nos aproximarmos do funcionamento da polícia política capixaba durante a Ditadura Militar (1964-1985), é necessário compreender, dentro dos limites deste trabalho, um pouco da experiência histórica da DOPS/ES no combate à subversão, assim como o seu processo de institucionalização e burocratização efetivado pelo estado brasileiro a partir da década de 1930.

O início da trajetória oficial da polícia política no Espírito Santo ocorre em 27 de novembro de 1930, no limiar do governo do interventor federal João Punaro Bley. Por meio do Decreto Estadual n. 129, é criado o cargo de Delegado de Ordem Social, subordinado à Delegacia Geral, que deveria conter, em terras capixabas, movimentos contestatórios da ordem estabelecida pela chamada Revolução de 1930. Entre 1935 e 1937, esse cargo foi elevado à condição de Delegacia Especial, originando a Delegacia de Ordem Política e Social do Espírito Santo (DOPS/ES). Tal medida reforçava a estruturação da polícia política capixaba refletindo a necessidade de combate ao crime político e ideológico, num contexto de fortes conflitos desse tipo no país. Assim, o estado respondia às tensões provocadas pelos embates entre grupos de extrema direita e extrema esquerda, respectivamente os integrantes da Ação Integralista Brasileira (AIB), e os indivíduos ligados à Ação Nacional Libertadora (ANL) e ao Partido Comunista do Brasil 
(PCB). Esses últimos serão os alvos preferenciais das forças de segurança do país, e assim da própria polícia política capixaba durante, praticamente, toda a sua história, expressando a ideologia anticomunista difundida entre os órgãos de repressão e na própria sociedade, que enfatizou o comunismo como grande ameaça aos interesses e à ordem nacional (FAGUNDES, 2011, p. 297-299).

Dessa forma, construía-se, desde a década de 1930, um dos pilares ideológicos da atuação da polícia política no Espírito Santo no século XX: o anticomunismo. Apesar de se prestar à vigilância e controle de diversos sujeitos durante a sua história, é sobre os indivíduos identificados com as organizações comunistas, que as atenções da DOPS/ES prioritariamente se voltaram em sua trajetória. O Levante Comunista de 1935 fomentado pela ANL elevou o combate ao comunismo e, principalmente, ao PCB - sua principal organização no país - a outro patamar. A partir desse fato, uma gama de recursos retóricos e práticos anticomunistas será manipulada pelos órgãos de segurança nacionais para identificar e difundir o comunismo como uma grande ameaça ao governo e à sociedade brasileira, devendo assim ser eliminado do território e do corpo social brasileiro (FAGUNDES, 2011, p. 300).

A centralidade atribuída ao comunismo como foco da subversão nacional pelas forças de segurança do país, e pela polícia política capixaba, fica evidente na manutenção e continuação da estruturação do aparelho repressor no período democrático que se abre a partir do fim da ditadura do Estado Novo, em 1945. Para Fagundes (2011, pp. 301302), de forma aparentemente contraditória, é justamente no ambiente democrático da década de 1950, que são definidos os aspectos fundamentais da atuação autoritária e repressiva da polícia política no Espírito Santo, definindo características que perdurarão com poucas mudanças até a extinção oficial da DOPS/ES no início dos anos 1990.

Dessa forma, após a queda do governo de Getúlio Vargas, no processo de democratização do país, em 1946, cria-se a Delegacia Especial em Ordem Política e Social do Espírito Santo (DEOPS/ES), resultante da unificação da antiga DOPS com a Delegacia de Estrangeiros, e as $1^{\mathrm{a}}$ e $2^{\mathrm{a}}$ Delegacias auxiliares, por meio do decreto-lei 16.230/46. Entre 1951 e 1954, o governo de Jones dos Santos Neves promoveu uma série de mudanças na Polícia Civil a partir da Lei Estadual 719, de 7 de março 1953. 
Doravante, estabeleceu-se a Delegacia de Ordem Política e Social como um dos setores especializados da Polícia Civil, retornando o uso da nomenclatura e da sigla DOPS/ES. Tal legislação ainda definia a estrutura administrativa da DOPS, que contaria com um gabinete do delegado, um cartório, e pessoal próprio. Suas atribuições também foram definidas. Entre elas, o órgão deveria cuidar de assuntos relacionados à ordem política e social, à economia popular e dos crimes e contravenções referentes ao trabalho, à paz, à fé e à administração pública. Caberia ainda a seus agentes: fiscalizar os embarques e desembarques por via terrestre e as pessoas em trânsito ou residentes em hotéis e habitações coletivas; controlar o fabrico, depósito, comércio e uso de explosivos inflamáveis, armas, munições, corrosivas, toxinas e entorpecentes; e monitorar serviço de estrangeiros e de porte individual de armas (FAGUNDES, 2011, p. 301).

A Lei Estadual 719/53 ainda atribuía à DOPS/ES a execução de todos os serviços secretos da Polícia Civil. Como observa Fagundes (2011), essa legislação além de permitir a intervenção da polícia política em diferentes esferas da vida social capixaba, ainda determinará um traço fundamental do seu funcionamento e organização ao respaldar legalmente o exercício de atividades clandestinas de vigilância e espionagem, que caracterizaram profundamente a atuação do órgão. Como veremos, essa característica operacional da DOPS/ES ficará evidente na documentação que registrou suas atividades cotidianas de controle social.

Durante a Ditadura Militar que se instalou a partir do golpe civil-militar de 1964, assim como ocorrera em outros estados, a experiência da DOPS/ES no combate à subversão na sociedade capixaba será aproveitada pelas Forças Armadas, que assumem o controle político do Estado brasileiro. Observando a documentação produzida pelo órgão nesse contexto, percebemos a inserção da polícia política capixaba na rede de informações a serviço da repressão no país, haja vista o forte intercâmbio de informações com outros órgãos de diferentes níveis hierárquicos. Mais do que isso, em âmbito estadual, ela estabelece-se como um verdadeiro tentáculo do aparelho repressor estatal no combate às oposições políticas na sociedade capixaba.

Dessa forma, entre os anos de 1964 e 1985, a DOPS/ES foi fundamental para a manutenção do regime ditatorial, atuando, especialmente, na vigilância e contenção de 
qualquer movimento contestatório do poder estabelecido. No final dos anos 1960, com os novos órgãos das Forças Armadas que são estruturados para o combate à subversão, ocorre o aumento do volume de informações sobre suspeitos, modificando a atuação da DOPS/ES, que passa a atender a um volume maior de pedidos de busca, apreensão, entre outras atividades operacionais e de informação (FAGUNDES, 2011, p. 304).

Pesquisas recentes têm contribuído para revelar o papel exercido pela polícia política capixaba no Espírito Santo entre os anos do regime ditatorial. Dessa forma, analisando parte da documentação da DOPS/ES no período, Fagundes (2011) aponta para a forma indistinta do órgão em definir os inimigos do governo, colocando como alvos de suas práticas de vigilância e repressão sujeitos e organizações diversas: vigiava-se a tudo e a todos. Assim,

[...] ao que tudo indica, o simples fato de um grupo de pessoas procurar se organizar, reivindicar e se mobilizar, independente de sua orientação ideológica, era motivo para compor a galeria de suspeitos de atentar contra ordem social. No vocabulário político dos agentes da repressão a palavra subversivo foi utilizada de maneira extremamente abrangente. (FAGUNDES, 2011, p. 31)

Nessa direção, o trabalho do pesquisador Jadson de Oliveira Adriani (2011) destaca os aspectos gerais da ideologia anticomunista que embasava a rotina das atividades de repressão da polícia política ao comunismo no Espírito Santo. O autor partiu da documentação produzida pela DOPS/ES para afirmar que na perspectiva desse órgão, os comunistas formavam um grupo de subversivos que iam além dos partidos e movimentos assumidamente comunistas, como por exemplo, o Partido Comunista Brasileiro (PCB), Partido Comunista do Brasil (PC do B), Partido Comunista Revolucionário (PCR). Na verdade, qualquer subversão era entendida como comunista. Dessa forma, por exemplo, o Movimento Democrático Brasileiro (MDB) era bastante monitorado pelos agentes da polícia política, na medida em que, aos seus olhos, na estrutura do sistema bipartidário, os quadros da organização estariam vulneráveis à infiltração de comunistas. 
Para além das organizações partidárias, outros segmentos e movimentos da sociedade capixaba foram classificados como subversivos, e por vezes, sob o prisma do anticomunismo, definidos como comunistas pelos agentes da DOPS/ES.

Tal perspectiva é reforçada pelas descobertas realizadas pela historiadora Erinaile Ribeiro da Silva (2013). A pesquisadora utilizou os arquivos da DOPS/ES para revelar as formas de atuação da militância da ala progressista da Igreja do Espírito Santo que motivaram o seu monitoramento pela polícia política entre os anos de 1974 e 1985. Dessa forma, constatou que, aos olhos dos seus agentes, a presença do elemento político de oposição no discurso e na atuação engajada dos diferentes atores da hierarquia eclesiástica ou da comunidade leiga na atividade pastoral, na articulação a movimentos sociais e partidos políticos, incitava o monitoramento dos passos seguidos por segmentos cristãos católicos, considerando-os como focos de subversão, rotulando-os como agitadores, e muitas vezes, como comunistas (SILVA, E., 2013, p. 122).

Nesse sentido, o estudo de Erinaile Silva (2013) nos permite mergulhar no universo das ações de vigilância e repressão lançadas pelas DOPS/ES. No período analisado pela referida historiadora, os arquivos da polícia política capixaba expressam, por exemplo, o caráter sigiloso da vigilância e do monitoramento de membros do clero e de leigos nas suas atividades pastorais através de organismos como as Comunidades Eclesiais de Base (CEBs) que vivem seu período de intensas atividades naquele contexto defendendo uma fé libertadora e emancipadora dos pobres. Eventos cristãos, missas e o cotidiano pastoral eram vigiados por agentes infiltrados que levantavam, clandestinamente, dados sobre as orientações litúrgicas e ideológicas fomentadas por bispos da arquidiocese de Vitória e dioceses de diferentes regiões do estado, em discursos proferidos em missas ou grandes eventos católicos como o Encontro Intereclesial de 1975, ocorrido na cidade Vitória-ES. Qualquer teor de crítica ao governo, seja qual fosse a esfera, fomentava indícios para a perseguição.

O registro de fotografias era utilizado para melhor identificação dos cristãos suspeitos de subversão nesses ambientes. Anotações de placas de automóveis, tipos de veículos utilizados e sua origem permitiam um melhor conhecimento dos passos dos movimentos católicos e suas origens. Apreensão de folhetins litúrgicos, panfletos, e 
materiais gerais de campanha serviam para aproximar os agentes policiais dos ideais defendidos por setores da Igreja do Espírito Santo, como para a materialização da construção do inimigo no seio do cristianismo capixaba, fomentando dossiês e ampliando as fontes de conhecimento das ameaças a combater. Prisões de suspeitos, e interrogatórios serviam à intimidação, ao mesmo tempo em que alimentavam a produção de informação que era intercambiada com diferentes órgãos de segurança e informação no estado e no país, reforçando o papel da DOPS/ES na rede de informações (SILVA, E., 2013).

Luiz Fernando da Silva Brumana (2016) verificou a atuação repressiva do órgão junto aos jornalistas capixabas nos anos 1970, em sua pesquisa sobre o trabalho do jornal Posição na cobertura do processo político brasileiro e capixaba nesse período. Seu trabalho contribuiu no sentido de nos aproximarmos do trabalho de vigilância exercido pela DOPS/ES sobre os trabalhadores e proprietários do mercado editorial no Espírito Santo.

Nessa direção, Brumana (2016) destaca que a perseguição aos membros do mercado editorial capixaba não distinguia funções. Todos estavam sujeitos à fiscalização, do repórter ao dono do jornal. Pedidos de busca levantavam dados como histórico, antecedentes criminais, orientações ideológicas, informações gerais da vida pessoal dos profissionais da comunicação investigados, e geraram dossiês, principalmente para aqueles identificados como mais "subversivos" ou ligados a movimentos e organizações assim classificados. Eventos como palestras e lançamento de livros de jornalistas também eram vigiados pelos agentes da DOPS/ES, gerando relatórios que tentavam detalhar sobre os olhos dos agentes os discursos, a movimentação, e os presentes.

Dados sobre as empresas de radiodifusão e jornais impressos também eram levantados. Os relatórios buscavam se alimentar da composição das diretorias dos principais jornais e revistas e posição ideológica de seus membros; empresa ou grupo a que pertence; empresa responsável pela composição da impressão; tiragem; periodicidade; linha editorial defendida no periódico; e outros dados julgados úteis (BRUMANA, 2016, p. 79). A DOPS/ES também vigiava entidades de classes ou trabalhistas ligadas ao ramo jornalístico, como a Associação Capixaba de Jornais do Interior e o 
Sindicato dos Jornalistas, fichando seus representantes e diretorias (BRUMANA, 2016, pp. 81-82).

Márcio Gomes Damartini (2016) atentou para a vigilância da DOPS/ES sobre os professores da rede pública estadual do Espírito Santo entre os anos de 1979 e 1981. O pesquisador apontou o roteiro de trabalho dos agentes do órgão diante da mobilização dos professores em movimentos paredistas no período: recolhimento de recorte de jornais e panfletos, infiltração de agentes em assembleias e movimentos grevistas, bem como a realização e socialização dos relatórios entre os órgãos da repressão, inclusive fora do Estado; e a organização da documentação em pastas, para facilitar a identificação. Nessas, era prática comum carimbar suas capas com termos como “confidencial”, "ação rotineira“, e identificar os vigiados como "elemento".

Estudando a reorganização do movimento estudantil na Universidade Federal do Espírito Santo - UFES entre os anos de 1976 e 1978, Ramilles Grassi Athaydes (2017) evidencia a vigilância da DOPS/ES sobre as entidades estudantis e suas lideranças. Tal trabalho incluía desde o monitoramento por agentes em assembleias e outros encontros do movimento, até o grampeamento de telefones, buscando rastrear informações sobre as futuras ações dos estudantes. Também se recolhiam materiais como folhetins, panfletos, jornais, e organizavam-se relatórios que identificavam lideranças, as reivindicações e as atividades dos estudantes no âmbito de suas mobilizações no interior e fora da universidade.

Outra contribuição historiográfica para o tema foi dada por José Carlos Rocha Júnior (2014). Esse pesquisador se debruçou sobre os arquivos da DOPS/ES a fim de investigar a trajetória da militância do PT no cenário político e social capixaba no início dos anos 1980. Ao mesmo tempo, almejou compreender o modus operandi da polícia política na vigilância e controle dos petistas no Espírito Santo.

Segundo Rocha Junior (2014, p. 16), o monitoramento das ações do partido pelos agentes do DOPS/ES devia-se, em primeiro lugar, à “persistente paranoia anticomunista” que gerava e difundia pelo corpo social o temor às palavras de ordem, discursos e símbolos. Ao mesmo tempo, a perseguição aos petistas se explicaria também pelo fato 
de o partido atrair militantes políticos já experientes e inimigos do regime, além de originar novos quadros de militância, aglutinando em torno de si diferentes oposições políticas ao governo. E por último, o fato de o PT ter sido criado a partir de um movimento que trouxe para o Espírito Santo pautas de reivindicações nacionais, como a anistia, a redemocratização, a luta por melhores salários e condições de trabalho, e que reproduziu grandes movimentos, como greves e campanhas de mobilização.

Em seu trabalho, Rocha Junior (2014) identificou o caráter sigiloso das investigações e da vigilância dos agentes da DOPS/ES sobre comícios, reuniões e campanhas do partido e dos setores ligados a ele, como os sindicatos; a apreensão de materiais como panfletos e documentos diversos; a identificação de lideranças e membros; e intercâmbio com a rede de repressão nacional e local. Dado interessante de sua pesquisa remete à continuidade da vigilância das ações do partido mesmo após o retorno ao pluripartidarismo e a garantia da legalidade da legenda petista no sistema político nacional na primeira metade da década de 1980. Mesmo em uma fase em que suas atividades entravam em declínio e o país encaminhava-se para a democratização, a repressão política da polícia política capixaba persistia.

Assim como ocorrera durante praticamente todo o século $X X$, O PCB era o movimento político mais perseguido pelos agentes da polícia política capixaba (ADRIANI, 2011, p. 41). Aproximando-se com a documentação produzida pela DOPS/ES ${ }^{11}$ sobre atuação do partido no Espírito Santo entre 1974 e 1985, executamos a partir daqui alguns breves apontamentos sobre as atividades de vigilância e repressão desenvolvidas pela polícia política capixaba sobre os militantes da referida sigla.

No monitoramento dos passos do PCB durante o regime militar, observa-se a atenção dada pela polícia política aos diversos aspectos que indicassem possíveis indícios da militância do partido na sociedade capixaba. Dessa forma, por exemplo, o Pedido de Busca No 60-S/2-74, de 27 de setembro de 1974, formalizado pelo $38^{\circ}$ Batalhão de Infantaria ao DOPS/ES e outras agências de informação no estado, solicita ações de

\footnotetext{
${ }^{11}$ A documentação que estamos analisando se concentra na Caixa 16 do fundo DOPS/ES do Arquivo Público do Estado do Espírito Santo (APEES), que se refere aos Movimentos Políticos vigiados por aquela delegacia. Os documentos que citaremos a seguir estão localizados no Dossiê 04 do referido acervo.
} 
vigilância e contenção sobre os movimentos dos comunistas em torno da campanha de arrecadação de fundos do PCB, chamada de "VII Mês Nacional de Finanças", que ocorreria em outubro daquele ano. Assim, caberia ao DOPS/ES, providenciar a identificação dos militantes do PCB atuantes no estado; executar prisões dos elementos identificados e coletar provas para submetê-los a processos; e procurar evitar o sucesso da referida campanha.

Observando essas informações, podemos identificar que a rotina de funcionamento da DOPS/ES envolvia, como já citado, o intercâmbio com outros órgãos repressores no combate à subversão. Entre suas atividades, podemos identificar o seu papel como membro da rede de informações, coletando e produzindo conhecimentos sobre o "inimigo", de modo a legitimar socialmente e juridicamente a repressão. Ademais, revela-se seu caráter operacional, na medida em que deveria executar também apreensões e prisões, e combater os passos seguintes da "ameaça comunista”.

As suspeitas sobre as possíveis estratégias clandestinas do partido ativavam operações que deveriam comprovar a veracidade dos indícios pela chamada "turma de operações" da DOPS/ES. Assim, por exemplo, o Informe de $n^{\circ}$ 52, de 29 de maio de 1975, oriundo do Centro de Informações do Departamento de Polícia Federal, acerca de uma possível orientação dos comunistas aos políticos do MDB para que não atacassem em discursos as Forças Armadas, e que se aproximassem da ala jovem militar, gerou a Ordem de Serviço $N^{\circ}$ 54, em 25 de setembro de 1975, pela qual o chefe do DOPS/ES determina que seus agentes busquem externamente averiguar a veracidade dos fatos. Assim como em reposta ao Pedido de Busca No 130 - S, de 08 de agosto de 1977, sobre uma orientação do PCB para que seus militantes e simpatizantes fomentassem greves nos setores de transportes e da indústria canavieira, teria se colocado de prontidão o setor operacional da polícia política para apurar se de fato isso estaria ocorrendo no Espírito Santo, segundo a Informação № 198 - SII/DOPS/ES, de 19 de agosto de 1977.

A coleta e apreensão de cartilhas, panfletos, resoluções políticas e jornais referentes ao PCB também eram utilizadas, municiando os arquivos da DOPS/ES de informações sobre os comunistas. Além disso, a desmontagem dos aparelhos que produziam e reproduziam esses documentos eram visados pelos órgãos de repressão. A 
informação N 338, de 16 de março de 1978, oriunda da Seção de Informações da Superintendência Regional do Departamento de Polícia Federal do Espírito Santo, orienta aos órgãos de informação estaduais para que localizem e neutralizem a produção das oficinas gráficas dos comunistas que porventura na área se instalassem.

Mesmo depois de o PCB retornar à legalidade e ser registrado no Superior Tribunal Eleitoral (STE), em 1985, a participação dos comunistas nas eleições municipais de Vitória daquele ano foi monitorada pela DOPS/ES. Nos arquivos do órgão, encontramos o material de campanha dos candidatos pecebistas para as eleições daquele ano, como se pode ver na figura 1. Isso expressa a persistência da manutenção do olhar vigilante dos agentes da polícia política capixaba sobre os representantes do comunismo, mesmo com o avanço da democratização do país. Tal situação nos leva a crer que a visão do comunismo como ameaça à segurança nacional mantinha-se viva.

Figura 1 - Material de campanha do PCB para as eleições municipais de Vitória em 1985.

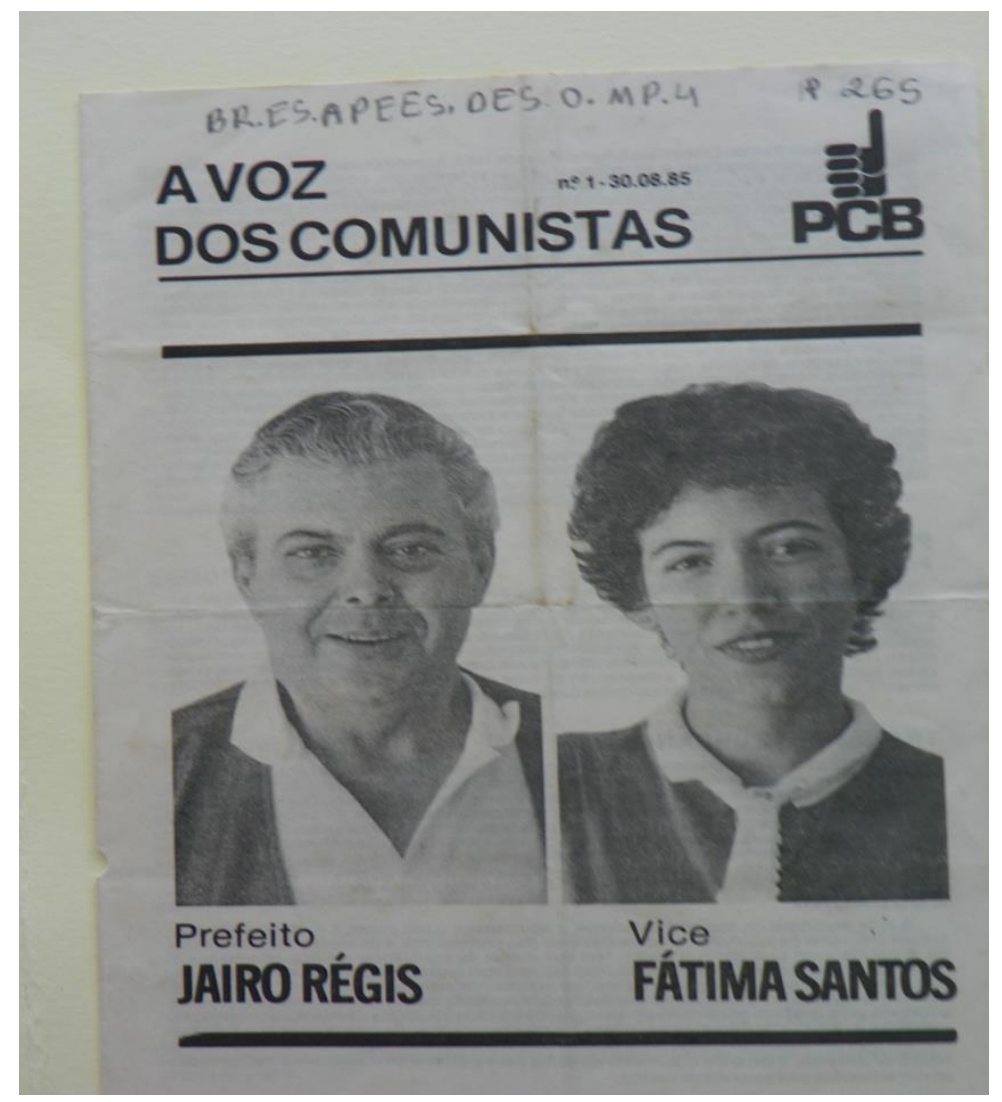

Fonte: Fundo DOPS/APEES. 
Ademais, no dossiê sobre o partido, é perceptível a intensa troca de informações sobre os militantes ou suspeitos de militância do PCB pelos órgãos de informação e repressão locais e nacionais.

\section{Considerações finais}

Apesar de afirmamos o objetivo de construir uma visão geral do funcionamento da DOPS/ES na sociedade capixaba durante os 21 anos de ditadura militar no país, é perceptível em nosso trabalho a atenção dada às atividades repressivas do órgão entre as décadas de 1970 e 1980. Isso ocorre pelos limites impostos pelo próprio acesso e disponibilização da documentação oficial, que, de fato, tem maior volume de registros referentes a esse momento.

Além disso, ressaltamos que, com a organização e a abertura dos arquivos, o processo de pesquisa histórica ainda tem muito por produzir a partir dos documentos confeccionados pelo órgão. Ao mesmo tempo, a coleta e interpretação de depoimentos dos agentes e das vítimas da polícia política no Espírito Santo contemporâneos ao referido período pode contribuir significativamente aos estudos dos historiadores interessados, por meio da História Oral.

A despeito dessas questões, entendemos que, de uma forma geral, podemos definir, mesmo que ainda de maneira parcial, que a DOPS/ES atuava no seio do aparelho repressivo estatal, montado durante a Ditadura Militar, tanto como um órgão de informação, como de segurança e repressão. Assim, a polícia política estadual se estendia como mais um braço repressor do Estado brasileiro, e um elo fundamental na rede de informações que fora ativada a serviço da repressão política, estabelecendo um constante intercâmbio de informações entre os níveis regionais e nacionais.

\section{Fontes documentais}

Arquivo Público do Estado do Espírito Santo. Fundo/Coleção: Delegacia de Ordem Política e Social do Espírito Santo. Série Movimentos Políticos. Caixa 16. Dossiê 04. 


\section{Referências}

ADRIANI, Jadson de Oliveira. O anticomunismo no Espírito Santo: a atuação da Delegacia de Ordem Política e Social (DOPS/ES). In: FAGUNDES, Pedro Ernesto (org.). Arquivos da repressão política do Espírito Santo. Vitória: PPHIS-UFES, GM Editora, 2011. p.35-42.

ANGELO, Vitor Amorim de. Luta armada no Brasil. São Paulo: Claridade, 2009.

ANGELO, Vitor Amorim de. Uma repressão em busca de justificativa: a relação entre ditadura militar e luta armada no Brasil. In: SIMPÓSIO NACIONAL DE HISTÓRIA -ANPUH, 26., 2011, São Paulo. Anais eletrônicos [...]. São Paulo: ANPUH, 2011. Disponível em: http://www.snh2011.anpuh.org/resources/anais/14/1307994258_ARQUIVO_artigo_snh2011 FINAL.pdf. Acesso em: 22 nov. 2019.

ARQUIVO NACIONAL. Centro de Referência das Lutas Políticas no Brasil (1964-1985). Memórias reveladas. Brasília: Arquivo Nacional, [201-]. Banco de dados. Disponível em: http://www.an.gov.br/mr/Multinivel/Exibe_Pesquisa_Reduzida.asp?v_CodReferencia_ID= 198. Acesso em: 28 de jul. 2014.

ATHAYDES, Ramilles Grassi. Documentando a subversão: a reorganização do movimento estudantil na Universidade Federal do Espírito Santo (1976-1978). 2017. Dissertação (Mestrado em História) - Programa de Pós-Graduação em História, Universidade Federal do Espírito Santo, Vitória, 2017.

BAUER, Caroline Silveira; GERTZ, René E. Fontes sensíveis da história recente. In: PINSKY, Carla Bassanezi; LUCA, Tania Regina de (orgs.). O historiador e suas fontes. São Paulo: Contexto, 2011. p.173-193.

BRUMANA, Luiz Fernando da Silva. O grito da resistência: o jornal Posição e a cobertura da abertura política no Espírito Santo (1976 a 1981). 2016. Dissertação (Mestrado em História) - Programa de Pós-Graduação em História, Universidade Federal do Espírito Santo, Vitória, 2016.

CAMARGO, Ana Maria de Almeida. Os arquivos e o acesso à verdade. In: SANTOS, Cecília MacDowell; TELES, Edson; TELES, Janaina de Almeida (org.). Desarquivando a ditadura: memória e justiças no Brasil. São Paulo: Aderaldo \& Rothschild, 2009. 272 p.

DAMARTINI, Márcio Gomes. A vigilância da polícia política aos trabalhadores em educação da rede estadual de ensino do Espírito Santo (1973-1981). 2016. Dissertação (Mestrado em História) Programa de Pós-Graduação em História, Universidade Federal do Espírito Santo, Vitória, 2016. 
FAGUNDES, Pedro Ernesto. Foi sempre assim: Modus Operandi da Polícia Política do Estado do Espírito Santo (1930-1985). In: FAGUNDES, Pedro Ernesto. Arquivos da repressão política no estado do Espírito Santo (1930-1985). Vitória: PPGHIS-UFES; GM Editora, 2011. p.11-34.

FAGUNDES, Pedro Ernesto. Universidade e repressão política: o acesso aos documentos da assessoria especial de segurança e informação da Universidade Federal do Espírito Santo (AESI/UFES). Tempo e Argumento, Florianópolis, v. 5, p. 295-316, 2013.

FICO, Carlos. Como eles agiam: os subterrâneos da Ditadura Militar: espionagem e polícia política. Editora Record, 2001.

GASPARI, Elio. A ditadura envergonhada. São Paulo: Companhia das Letras, 2002.

JOFFILY, Mariana. O aparato repressivo: da arquitetura ao desmantelamento. A ditadura que mudou o Brasil, v. 50, p. 158-171, 2014.

JOFFILY, Mariana. No centro da engrenagem: os interrogatórios na Operação Bandeirante e no DOI de São Paulo (1969-1975). Rio de Janeiro: Arquivo Nacional; São Paulo: Edusp, 2013

MENDONÇA, Eliane Rezende Furtado de. Documentação da polícia política do Rio de Janeiro. Revista Estudos Históricos, v. 12, n. 22, p. 379-388, 1998.

MOTTA, Rodrigo Patto Sá. Em guarda contra o "perigo vermelho": o anticomunismo no Brasil (1917-1964). Editora Perspectiva, 2002.

MOTTA, Rodrigo Patto Sá. O ofício das sombras. Revista do Arquivo Público Mineiro, v. 42, n. 1, p. 52-67, 2006.

ROCHA JUNIOR, José Carlos. No encalço dos companheiros: militantes do partido dos trabalhadores (PT) sob vigilância da delegacia de ordem política e social do Espírito Santo (DOPS/ES) - (1978-1985). 2014. Dissertação (Mestrado em História) - Programa de PósGraduação em História, Universidade Federal do Espírito Santo, Vitória, 2014.

SILVA, Erinaile Ribeiro da. Fé e repressão política: atuação de militantes cristãos católicos sob o olhar da delegacia de ordem política e social do estado do Espírito Santo - DOPS/ES - (1974 - 1985). 2013. Dissertação (Mestrado em História) - Programa de Pós-Graduação em História, Universidade Federal do Espírito Santo, Vitória, 2013.

SILVA, Marcília Gama da. Informação, repressão e memória: a construção do estado de exceção no Brasil na perspectiva do DOPS-PE (1964 - 1985). Tese (Doutorado em História) 
- Programa de Pós-Graduação em História, Universidade Federal de Pernambuco, Recife, 2007.

SILVA, Marcília Gama da. O DOPS-PE e a rede de Informações: olhos e ouvidos a serviço da repressão no período de 1964-1985. Diálogos, Maringá, v. 15, n. 2, p.267-292, maio/ago. 2011.

VALFRÉ, Vinícius. Veja onde funcionavam os porões da ditadura. Portal Gazeta Online. 19 mar. 2014. Disponível em: http://gazetaonline.globo.com/_conteudo/

2014/03/noticias/cidades/1482369-veja-onde-funcionavam-os-poroes-da ditadura.html. Acesso em: 21 nov. 2019.

XAVIER, Marília. Antecedentes institucionais da polícia política. DOPS. A Lógica da Desconfiança. $2^{\text {a }}$ ed., Rio de Janeiro: Secretaria de Estado da Justiça, Arquivo Público do Estado, p. 32-41, 1996.

Recebido em: 03/03/2020

Aprovado em: 15/06/2020

Universidade do Estado de Santa Catarina - UDESC

Centro de Ciências Humanas e da Educação - FAED

PerCursos

Volume 21 - Número 46 - Ano 2020 revistapercursos@gmail.com 